\title{
Determination of Polyoxin B in Cucumber and Soil Using Liquid Chromatography Tandem Mass Spectrometry Coupled with a Modified QuEChERS Method
}

\author{
Shiming Song, Zhaojie Chen, Jie Wei, Yuhao Lei, Cheng Deng, Huihua Tan and Xuesheng Li* \\ Institute of Pesticide and Environmental Toxicology, Guangxi Key Laboratory Cultivation Base of Agro-Environment and \\ Agro-Product Safety, Guangxi University, Nanning 530005, China
}

Received: 10 December 2017; accepted: 05 January 2018

\begin{abstract}
A sensitive and effective method based on a modified QuECHERS (quick, easy, cheap, effective, rugged, and safe) method for the determination of polyoxin B in cucumber and soil using liquid chromatography tandem-mass spectrometry (LC-MS/MS) was developed and validated. Samples were extracted using $1 \%$ formic acid in ultrapure water and purified via reversed-dispersive solid phase extraction (r-dSPE) using $\mathrm{C}_{18}$. Recovery of polyoxin $\mathrm{B}$ ranged from $83.0 \%$ to $112.1 \%$ with relative standard deviation (RSD) $(n=5)$ of $3.0-5.2 \%$. The limit of quantification (LOQ) and the limit of detection (LOD) were 0.01 and $0.003 \mathrm{mg} / \mathrm{kg}$ for cucumber and soil, respectively. The method was subsequently applied for real sample analysis. The dissipation experiments showed that half-lives of polyoxin B in cucumber and soil were 2.5-5.0 days. The terminal residues of polyoxin B at preharvest intervals (PHIs) of 3 days and 5 days in cucumber were less than $0.05 \mathrm{mg} / \mathrm{kg}$. We therefore suggest that the developed method can be extrapolated to other agricultural crops or food for routine analysis. It also can be used to determine the PHIs. Moreover, these results will aid in establishing the maximum residue limit (MRL) for cucumber in China.
\end{abstract}

Keywords: Polyoxin B, cucumber, soil, dissipation experiments, terminal residues, QuECHERS, LC-MS/MS

\section{Introduction}

Polyoxins (POLs), which are a group of nucleoside peptide antifungal antibiotics, were discovered in the culture of Streptomyces cacaoi var. asoensis in 1963 [1]. They have been used as practical fungicides in China or over the world for these antibiotics show high activity against phytopathogenic fungi. There are at least 12 components of POLs, which are designated alphabetically, Pol-A to -P [2] (see in Figure 1). Polyoxins are mainly divided into two categories in agricultural production: one is based on polyoxin $\mathrm{A}$ and $\mathrm{B}$, and the other is polyoxin D to F. Among the various components of polyoxins, polyoxin B shows the highest antimicrobial activity [3] and is very soluble in water whereas practically insoluble in common organic solvents such as methanol, ethanol, butanol, acetone, chloroform, benzene, and ether $[4,5]$. It is stable in solution over a $\mathrm{pH}$ range of 1 to 8 [6]. Polyoxin $\mathrm{B}$ is not toxic to vertebrates and mammalian systems. Therefore, it is a logical candidate for antifungal agents for the treatment of systemic fungal infections [7]. Polyoxin B is practically used for control of various fungal diseases of fruit, vegetables, and other agricultural crops [8]. Currently, polyoxin B has already been registered in China for use against powdery mildews and downy mildews on ornamental and vegetable crops $[9,10]$. In addition, a commercial preparation of polyoxin (containing polyoxin $\mathrm{B}$ ) or polyoxin $\mathrm{B}$ has been widely used to protect the crops from phytopathogenic fungi.

Recently, research of polyoxin B mainly concentrated on isolation [8], effect $[3,11,12]$, and synthesis [13, 14], while research of polyoxin B focused on residues in crops was seldom. Therefore, the development of an analytical method for quantitative determination of polyoxin $\mathrm{B}$ is essential and critical to its residues-related research and development. For detection of polyoxin $\mathrm{B}$, high-performance liquid chromatography (HPLC) [15], capillary electrophoresis with

\footnotetext{
* Author for correspondence: 1xsnngx@163.com
}

electrochemiluminescence (CE-ECL) [16], and microbiological [7] assay have been used. For the method of CE-ECL, pretreatment is tedious and not effective. Microbiological method is simple and cheap but not suitable to determine residues in agricultural crops and food. The HPLC method is excellent efficiency and high recovery. However, Yu et al. [15] were only concentrating on analytical method, but the determination of polyoxin B in real samples was not applied. Thus, it is needed to establish a rapid, simple, cheap, and sensitive method for determination of polyoxin $\mathrm{B}$, especially for agricultural crops and food.

The QuEChERS (quick, easy, cheap, effective, rugged, and safe) method has been used for the extraction of wide variety of pesticides in vegetables and fruit $[17,18]$. It involves miniaturized extraction with acetonitrile, liquid-liquid portioning, and a cleanup process, which is carried out by mixing the acetonitrile with loose sorbents (such as primary secondary amine [PSA], graphitized carbon black [GCB], $\mathrm{C}_{18}$, multiwalled carbon nanotubes [MWCNT]) before gas chromatography (GC) and liquid chromatography (LC) injection [19, 20]. The cleanup step of QuEChERS method is based on reverseddispersive solid phase extraction ( $\mathrm{r}-\mathrm{dSPE})$, which absorbs the interference substances in matrices, rather than analytes.

Currently, maximum residue limits (MRLs) for polyoxins (containing polyoxin B) have not been established in China and throughout the word (except Japan) [21]. However, "temporary" MRLs for polyoxins $(0.5 \mathrm{mg} / \mathrm{kg})$ were established by China, and polyoxin B was regarded as a residual assessment target [22]. Therefore, monitoring, assessing, and controlling the pollution status are helpful when establishing the MRL and also predict or reduce the amount of antibiotics present in agro-ecosystems and their resulting potential human health impacts [23]. To our knowledge, residual of polyoxin D in crops has been reported [23]. However, no research on analytical method and determination of polyoxin B in food or fruit was reported. In this study, a modified QuEChERS method

This is an open-access article distributed under the terms of the Creative Commons Attribution-NonCommercial 4.0 International License (https://creativecommons.org/licenses/by-nc/4.0/), which permits unrestricted use, distribution, and reproduction in any medium for non-commercial purposes, provided the original author and source are credited, a link to the CC License is provided, and changes - if any - are indicated. 


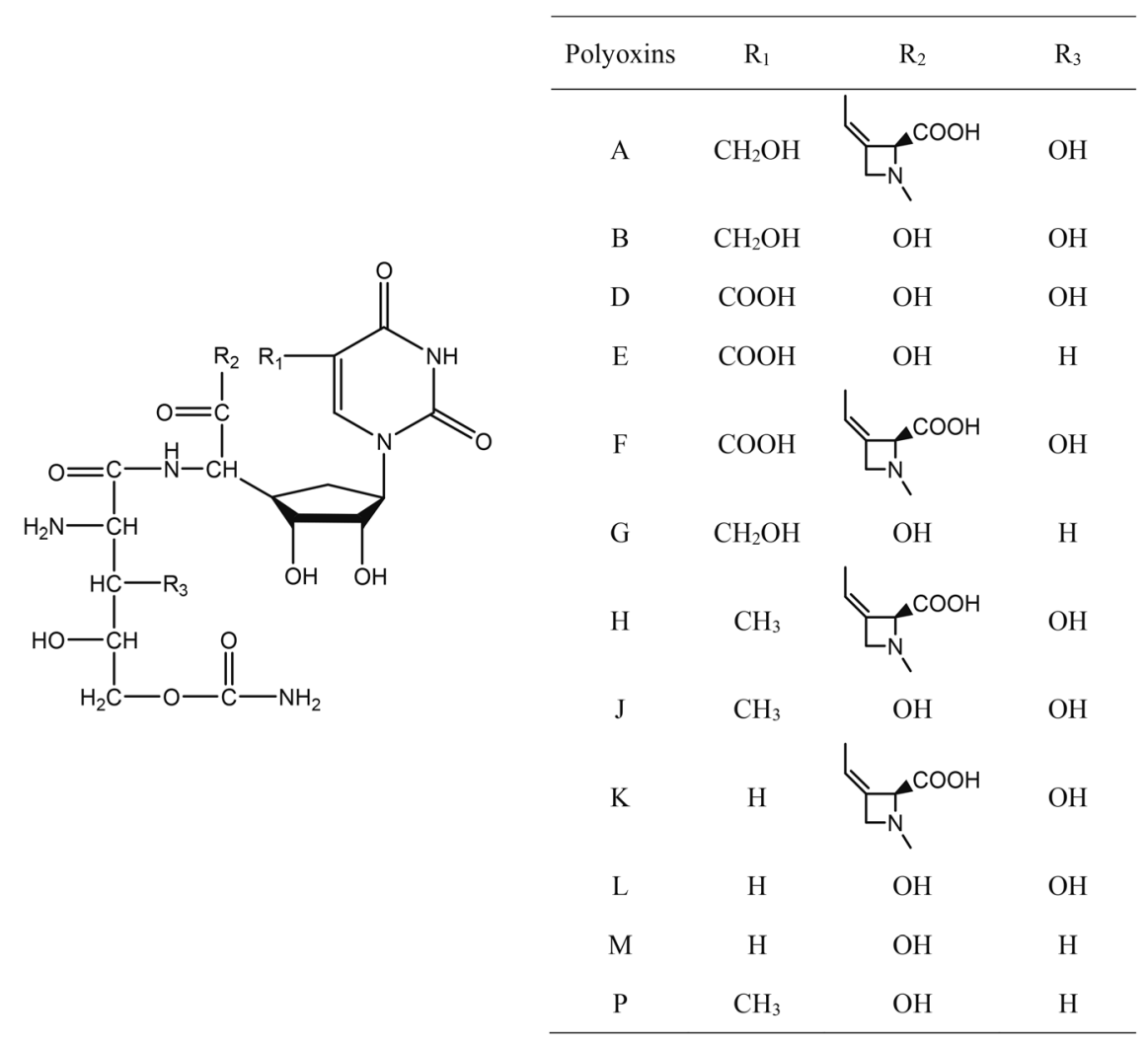

Figure 1. Chemical structures of polyoxins

preparation approach coupled with LC-MS/MS for analysis of polyoxin B in cucumber and soil was developed. Meanwhile, negative ion mode $\left(\mathrm{ESI}^{-}\right)$and positive ion mode $\left(\mathrm{ESI}^{+}\right)$were compared with mass spectrometry. This method was successfully used to research the role of polyoxin B in cucumber and soil and find out the different residues in plant and the environment after applied. This study would provide the basis for safety evaluation and helpfully establish MRL of polyoxin B.

\section{Experimental}

2.1 Chemicals and Reagents. Polyoxin B (29\%) standard material was purchased by Dr. Ehrenstorfer Germany. Formic acid and methanol were of HPLC grade (Merck, Germany). Polyoxin (1\%) aqueous solution was commercially available. Analytical-grade methanol was provided by Chengdu Kelong Chemical Reagent Company (Chengdu, China). Ammonia was analytical grade and provided by Merck Chemicals (Shanghai) Co., Ltd. Ultrapure water $(0.22 \mu \mathrm{m})$ was prepared using a Milli-Q treatment system (Millipore, USA). Primarysecondary amine (PSA), graphitized carbon black (GCB), $\mathrm{C}_{18}$, and multiple-walled carbon nanotubes (MWCNTs) were supplied by Agilent Technologies (Santa Clara, CA, USA).

2.2 Field Experiments and Sampling. Field trials, including dissipation and terminal residues studies, were designed according to pesticide label. The supervised field trials were conducted in Guangxi (GX), Hunan $(\mathrm{HN})$, and Anhui (AH) provinces of China in 2012 and 2013. The experimental area was designed with three replicated plots and a control plot without pesticide treatment. A buffer area was employed to separate each plots. The area of the experimental plot was $20 \mathrm{~m}^{2}$. In the dissipation experiments, the dosage of polyoxin was $225 \mathrm{~g}$ a.i./ha (highest recommended dosage) with a one-time spray. About $2 \mathrm{~kg}$ of testing cucumber and $500 \mathrm{~g}$ soil samples were collected randomly from five points in each plots at intervals of $2 \mathrm{~h}, 1,3,5,10$, and 14 days after applied to dissipation experiments. As to the terminal residues experiments, the dosages were 150 and $225 \mathrm{~g}$ a.i./ha with three-time spray, and the interval of application was 7 days. About $1 \mathrm{~kg}$ samples were collected in each plot at 2, 3, and 5 days after application. Cucumber samples were cut into small pieces and homogenized. Soil samples were screened with $1 \mathrm{~mm}$ diameter, and quadrates were used to take $300 \mathrm{~g}$. All samples were stored at $-20{ }^{\circ} \mathrm{C}$ in the freezer and analyzed within a month.

2.3 Samples Preparation and Purification. Five grams of previously homogenized samples (cucumber or soil) were weighed in $50 \mathrm{~mL}$ teflon centrifuge tube, to which $5 \mathrm{~mL}$ volume of $1 \%$ formic acid in ultrapure water was added. Also, the tube was shaken vigorously for $2 \mathrm{~min}$. The tube then was centrifuged for $3 \mathrm{~min}$ at $4500 \mathrm{r} / \mathrm{min}$. After centrifugation, $1.5 \mathrm{~mL}$ of the clarified supernatant was transferred to a $2.0 \mathrm{~mL}$ microcentrifuge tube containing $20 \mathrm{mg} \mathrm{C}$. The mixture was shaken vigorously for $1 \mathrm{~min}$ and centrifuged for $5 \mathrm{~min}$ at $8000 \mathrm{rpm}$ in a microcentrifuge. Finally, $1.0 \mathrm{~mL}$ of the clarified supernatant was filtered through a $0.22 \mu \mathrm{m}$ filter membrane, and $1.0 \mathrm{~mL}$ of the extract was placed into an LC vial to carry out the chromatographic analysis.

2.4 LC-MS/MS Analytical Conditions. The liquid chromatographic performance was conducted using an Agilent 1290 Series Rapid Resolution LC System (CA, USA). Analytes were separated on a Poroshell 120 Hilic column (50 $\mathrm{mm} \times 0.21 \mathrm{~mm}, 2.7 \mu \mathrm{m}$, Agilent) kept in an oven at $25{ }^{\circ} \mathrm{C}$. The mobile phase was $0.1 \%$ formic acid in watermethanol $(60: 40)$ at a flow rate was $0.2 \mathrm{~mL} / \mathrm{min}$, and the injection volume was $2 \mu \mathrm{L}$

The effluent from the LC system was introduced into an Agilent G6460C Triple Quadrupole LC/MS (QQQ) in positive electrospray ionization $\left(\mathrm{ESI}^{+}\right)$mode using multiple reaction monitoring (MRM) with two mass transitions. Among the two mass transitions, one product ion having the most intensity and another of low intensity were used as quantifier and qualifier ions, respectively. Pesticide standard solutions were directly infused into the QQQ for the optimal mass 
spectrometry instrument parameters. Nitrogen was employed as a nebulizer and drying gas at $15 \mathrm{psi}$ and $350{ }^{\circ} \mathrm{C}$, and the gas flow was $13 \mathrm{~mL} / \mathrm{min}$. The capillary was set to $4 \mathrm{kV}$. Both MS1 and MS2 quadrupoles were maintained at unit resolution. The other conditions are presented in Table 1.

2.5 Statistical Analysis. Since no matrix effect was observed for cucumber and soil samples, a non-matrixmatched calibration standard was directly used for the quantification of the residues in cucumber and soil samples by LC-MS/MS.

The dissipation kinetics of polyoxin B in cucumber and soil were determined by plotting the residue concentration against

Table 1. MRM transitions and other LC-MS/MS parameters

\begin{tabular}{lcccc}
\hline Pesticide & $\begin{array}{c}t_{\mathrm{R}} \\
(\mathrm{min})\end{array}$ & $\begin{array}{c}\text { Fragmentor } \\
(\mathrm{V})\end{array}$ & $\begin{array}{c}\text { Quantifying } \\
\text { transition }^{a}\end{array}$ & $\begin{array}{c}\text { Qualification } \\
\text { transition }^{a}\end{array}$ \\
\hline Polyoxin B & 0.82 & 106 & $508 / 490(16)$ & $508 / 305(20)$ \\
${ }^{a}$ Collision energy (eV) & is given in parentheses. \\
\hline
\end{tabular}

time, and the maximum squares of correlation coefficients found were used to determine the equations for the best fit curves. The dissipation was calculated by the first-order rate equation. The first-order kinetics are confirmed further by performing graphically from the equation of $C_{t}=C_{0} e^{-k t}$, where $C_{t}$ represents the concentration of the pesticide residue at time $t, C_{0}$ represents the initial concentration after application, and $k$ is the degradation rate constant in per day. The half-life $\left(t_{1 / 2}\right.$, $\left.t_{1 / 2}=\ln (2) / k\right)$ was calculated from the $k$ value for each experiment.

\section{Results and Discussion}

3.1 Method Validation. Linearity was evaluated by analyzing five standard solutions in the range of $0.01-1 \mathrm{mg} / \mathrm{L}$ $(0.01,0.05,0.1,0.5$, and $1 \mathrm{mg} / \mathrm{L})$ for ultrapure water, performing three replicates at each level. The calibration curve for polyoxin B was $y=4299 x+233.34$ with coefficient of determination $\left(R^{2}\right)$ of 0.998 . Quantification was accomplished

Table 2. The mean recovery and RSDs at three spiked levels in cucumber and soil

\begin{tabular}{|c|c|c|c|c|c|c|}
\hline \multirow[t]{2}{*}{ Polyoxin B } & \multicolumn{3}{|c|}{ Cucumber } & \multicolumn{3}{|c|}{ Soil } \\
\hline & $0.01 \mathrm{mg} / \mathrm{kg}$ & $0.1 \mathrm{mg} / \mathrm{kg}$ & $1 \mathrm{mg} / \mathrm{kg}$ & $0.01 \mathrm{mg} / \mathrm{kg}$ & $0.1 \mathrm{mg} / \mathrm{kg}$ & $1 \mathrm{mg} / \mathrm{kg}$ \\
\hline Mean recovery, $\%(\mathrm{RSD}, \%)(n=5)$ & $92.5(5.2)$ & $112.1(3.0)$ & $88.0(3.6)$ & $100.1(3.7)$ & $98.7(3.4)$ & $83.0(5.2)$ \\
\hline
\end{tabular}
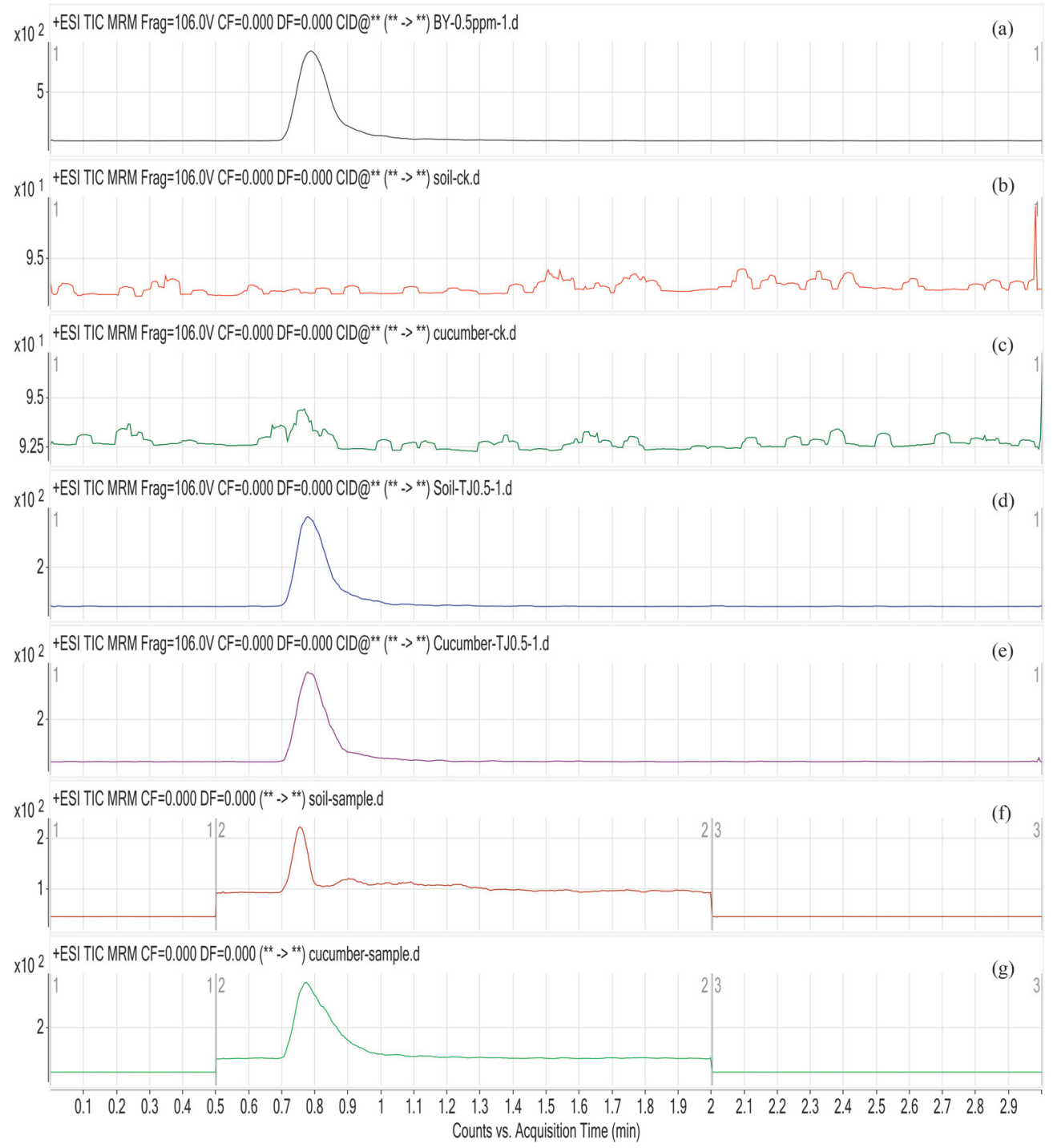

Figure 2. LC-MS/MS chromatograms of polyoxin B: (a) $0.1 \mathrm{mg} / \mathrm{L}$ standard; (b) soil control butterbur; (c) cucumber control butterbur; (d) fortified soil sample at $0.1 \mathrm{mg} / \mathrm{kg}$; (e) fortified cucumber sample at $0.1 \mathrm{mg} / \mathrm{kg}$; (f) triple-dosed field-treated soil sample ( $2 \mathrm{~h}$ ); and (g) triple-dosed fieldtreated cucumber sample $(2 \mathrm{~h})$ 
using the standard curve constructed by plotting analyte concentrations against peak areas.

The limit of detection (LOD) and limit of quantification (LOQ) for polyoxin B were defined by the ratio of the signalto-noise $(\mathrm{S} / \mathrm{N})$ of 3 and 10 from the lowest concentration levels of the spiked samples. The LOD and LOQ were 0.003 and $0.01 \mathrm{mg} / \mathrm{kg}$, respectively.

Recovery experiments were performed by fortifying the samples at three levels $(0.01,0.1$, and $1 \mathrm{mg} / \mathrm{kg}$ ) of polyoxin B. The accuracy was evaluated by the recoveries (\%), and the precision was expressed by relative standard deviations (RSDs) (\%) of the spiked samples. The intra-day precision was studied by comparing the standard deviation of the recoveries from the spiked samples analyzed during the same day. As shown in Table 2, the mean recoveries of polyoxin $B$ in
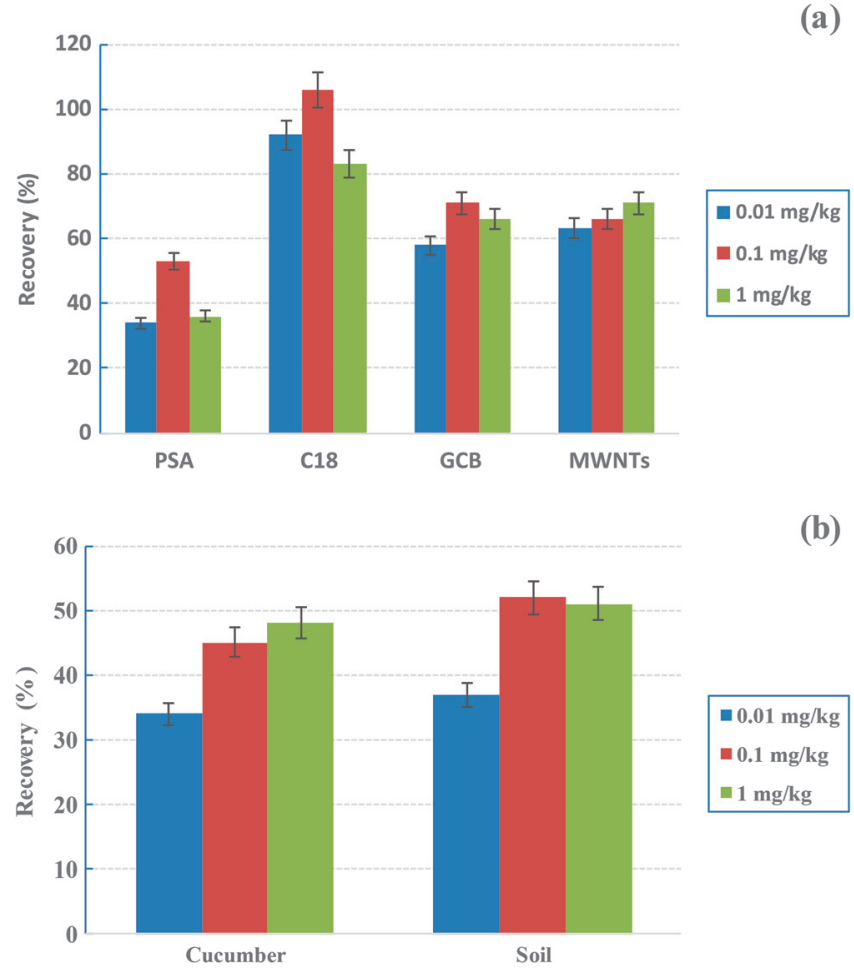

Figure 3. Optimization of the r-dSPE procedure: (a) effects of r-dSPE sorbents on the recoveries of polyoxin B at spiked level $(n=3)$ of $0.01 \mathrm{mg} / \mathrm{kg}, 0.1 \mathrm{mg} / \mathrm{kg}$, and $1 \mathrm{mg} / \mathrm{kg}$ without matrix inclusion; (b) effects of $\mathrm{C}_{18}$ sorbents on the recoveries of polyoxin B at spiked level $(n=3)$ of $0.01 \mathrm{mg} / \mathrm{kg}, 0.1 \mathrm{mg} / \mathrm{kg}$, and $1 \mathrm{mg} / \mathrm{kg}$ for cucumber and soil samples cucumber and soil ranged from $83.0 \%$ to $112.1 \%$ with RSD $(n=5)$ of $3.0-5.2 \%$, which were in the satisfactory range expected for residue analysis. Moreover, as presented in Figure $2 \mathrm{a}$ to $\mathrm{c}$, the chromatogram of the control soil and cucumber samples shows no interference peaks either at or around the retention time of the analytical compound, confirming the specificity of the method.

Polyoxin B is eluted in the front of the LC-MS/MS chromatograms and most probably together with other water soluble compounds, and the peak shape was poor (see in Figure $2 \mathrm{f}$ and $\mathrm{g}$ ), which might be responsible for a little interference from field-treated samples. From Figure 2a, d, and e, we could conclude that no matrix effect was observed for cucumber and soil samples. In a word, the validation data show that the developed method could be successfully applied for the determination of polyoxin B in soil and cucumber.

3.2 Extraction and Purification Procedure Optimization of Polyoxin B. For the extraction procedure of polyoxin B, a modified QuEChERS (quick, easy, cheap, effective, rugged and safe) method was investigated. At first, samples were extracted using $0.1 \%$ formic acid in acetonitrile and sodium chloride. As mass spectrometry is considered selective and specific, with the exception of a clean chromatogram. However, a large number of interference was observed at the retention time of the polyoxin B in cucumber and soil samples. Therefore, the purification procedure to remove these coextractants is necessary and important.

The QuEChERS method can be used to remove matrix interferences through a variety of dispersive cleaning sorbents $[24,25]$. Thus, r-dSPE sorbents such as PSA, GCB, $\mathrm{C}_{18}$, and MWCNTs were investigated without matrix inclusion [26, 27]. As presented in Figure 3, the $\mathrm{C}_{18}$ provided acceptable recovery $(83-106 \%)$ of the polyoxin B. However, when it was combined with the previously fortified cucumber and soil matrix extract, interference was reduced, but the recovery of polyoxin B was lower $(34-52 \%)$. This may be due to the hydrophilic characteristics of polyoxin $\mathrm{B}$, which bring about its failure to split into organic phase from aqueous phase. Therefore, four different solvents were selected to evaluate the extraction efficiencies (tested at spiked level $0.1 \mathrm{mg} / \mathrm{kg}$ ) without purification. Also, the four different solvents were $1 \%$ formic acid in ultrapure water, methanol-ultrapure water, $50: 50 \mathrm{v} / \mathrm{v}$, ultrapure water, and $1 \%$ ammonium hydroxide in ultrapure water. Direct injection to the MS/MS was possible as the extract solution was diluted, and the extraction did not contain any non-polar or colored components. From Figure 4, we could conclude that 1\% formic acid in ultrapure water gave a greater recovery $(98-114 \%)$ than among

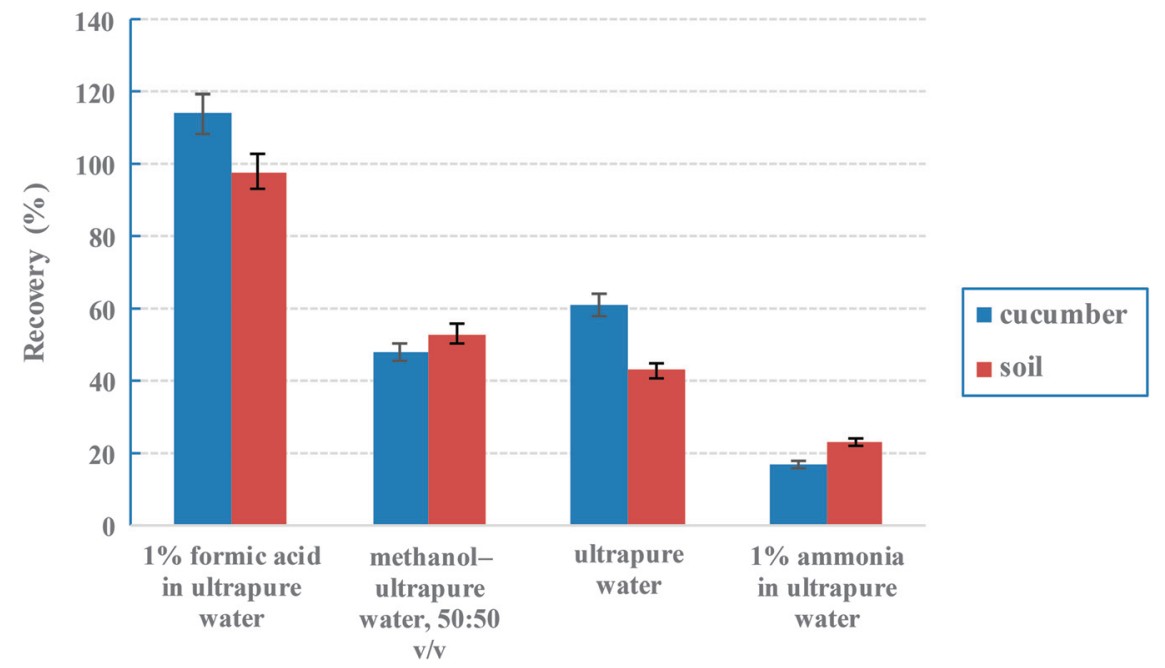

Figure 4. Effect of different extraction solvents for polyoxin B in cucumber and soil at $0.1 \mathrm{mg} / \mathrm{kg}$ level $(n=5)$ 
methanol-ultrapure water, 50:50 v/v (48-53\%), ultrapure water (43-61\%), and 1\% ammonia in ultrapure water (17-23\%). In addition, the use of $1 \%$ formic acid in ultrapure water with $\mathrm{C}_{18}$ (20 mg) had little effect on recoveries. Finally, 1\% formic acid in ultrapure water extract of soil and cucumber was purified using a $\mathrm{C}_{18}$ without the requirement for sodium chloride, reconstitution, or partitioning, although the use of $\mathrm{C}_{18}$ for extraction may be questionable as polyoxin $\mathrm{B}$ and other water soluble compounds will flow directly through the column. However, it provided a much cleaner extract compared to a non- $\mathrm{C}_{18}$ extraction.

3.3 Mass Spectrometry Optimization. To optimize the mass spectrometry, $0.5 \mathrm{mg} / \mathrm{L}$ standard solution of polyoxin $\mathrm{B}$ was injected into a mass spectrometer through direct infusion via a syringe pump at a flow rate of $0.2 \mathrm{~mL} / \mathrm{min}$. The mass spectrometric parameter option was initially performed by full scan for polyoxin $\mathrm{B}$ in the range of $\mathrm{m} / \mathrm{z} 100-550$ under the positive ion mode $\left(\mathrm{ESI}^{+}\right)$and negative ion mode (ESI $\left.{ }^{-}\right)$. The $[\mathrm{M}+\mathrm{H}]^{+}$ion $(\mathrm{m} / \mathrm{z}$ values of 508.2$)$ and $[\mathrm{M}-\mathrm{H}]^{-}$ion $(\mathrm{m} / \mathrm{z}$ values of 506.1) were selected as the precursor ion for polyoxin B. The product ion mass spectra for polyoxin B were at $\mathrm{m} / \mathrm{z}$ values of 463.1, 216.6, and 140.6 (see in Figure 5a) in negative ion mode, while the product ion mass spectra for polyoxin B were at $\mathrm{m} / \mathrm{z}$ values of $489.9,366.3$, and 305.3 (see in Figure $5 \mathrm{~b}$ ) in the positive ion mode. As the abundance and response of product ion mass spectra in negative ion mode were lower than in the positive ion mode. Finally, the positive ion mode was selected to analysis polyoxin B. Product ion $(\mathrm{m} / \mathrm{z}$ values of 489.9, 366.3, and 305.3) mass spectra for analytes were obtained in electrospray ionization using collision-induced dissociation (CID). The collision energy for collision-induced dissociation was optimized for two selective ion transitions for polyoxin B. The intensity of the signal at $\mathrm{m} / \mathrm{z} 489.9$ was higher than that at $m / z 366.3$ and 305.3 (see in Figure 5b). Thus, the transition at $\mathrm{m} / \mathrm{z} 489.9$ was selected as the quantitation ion, while the transition at $\mathrm{m} / \mathrm{z} 305.3$ was selected as the confirmation ion. The characteristic ion transition, fragmentor voltage, and collision energy for polyoxin B during MRM acquisition are shown in Table 1.

In total, the ionization of polyoxin B in the positive mode electrospray ion source was investigated. Conditions for interfacing the LC system to the MS were evaluated. The developed method was also highly selective with the monitoring of a specific MRM of polyoxin B, which was essential to reduce the risk of false-positive results.

3.4 Dissipation and Terminal Residues of Polyoxin B in Cucumber and Soil. The dissipation equations and half-lives of polyoxin B are listed in Table 3. Typical dissipation curves of polyoxin B in soil and cucumber are shown in Figure 6. Initial deposits of polyoxin $\mathrm{B}$ residues in cucumber were in the range of 0.48 to $0.87 \mathrm{mg} / \mathrm{kg}$ in Guangxi, Hunan, and Anhui provinces of China in 2012 and 2013. Also, half-lives were observed to be ranged from 2.5 to 4.3 days. In addition, the initial deposits of polyoxin B residues in soil were between 0.56 to $0.83 \mathrm{mg} / \mathrm{kg}$, and half-lives were range of 3.7 to 5.0 days. Dissipation cures of polyoxin B in cucumber and soil were resembled. The higher initial deposits of polyoxin B residues in cucumber were found on Anhui province in 2012 and 2013. This may be related to the hydrophilic characteristics of polyoxin B and the climate condition in Anhui. The average rainfall in Anhui [28, 29] is less than that in Guangxi $[30,31]$ and Hunan $[32,33]$. Moreover, the higher initial deposits of polyoxin B residues in soil were also found on Anhui province in 2012 and 2013. This may be related to soil characteristics or microorganisms. Soil type, $\mathrm{pH}$ values, temperature, and organic matter in the soil may show to be the major factors influencing the degradation of polyoxin B. Soil in Guangxi was sandy $(\mathrm{pH}=4.88-6.60)$ [34], that in Hunan was lateritic soil $(\mathrm{pH}=4.68-5.35)$ [34], while that in Anhui was brown forest soil $(\mathrm{pH}=7.51-8.50)$ [35]. All of soil characteristics may cause rapid degradation of polyoxin $\mathrm{B}$.

The experimental data of polyoxin $\mathrm{B}$ residues at preharvest intervals (PHIs) of 2 days were between 0.06 and $0.12 \mathrm{mg} / \mathrm{kg}$, but PHIs of 3 days and 5 days did not exceed the "temporary"
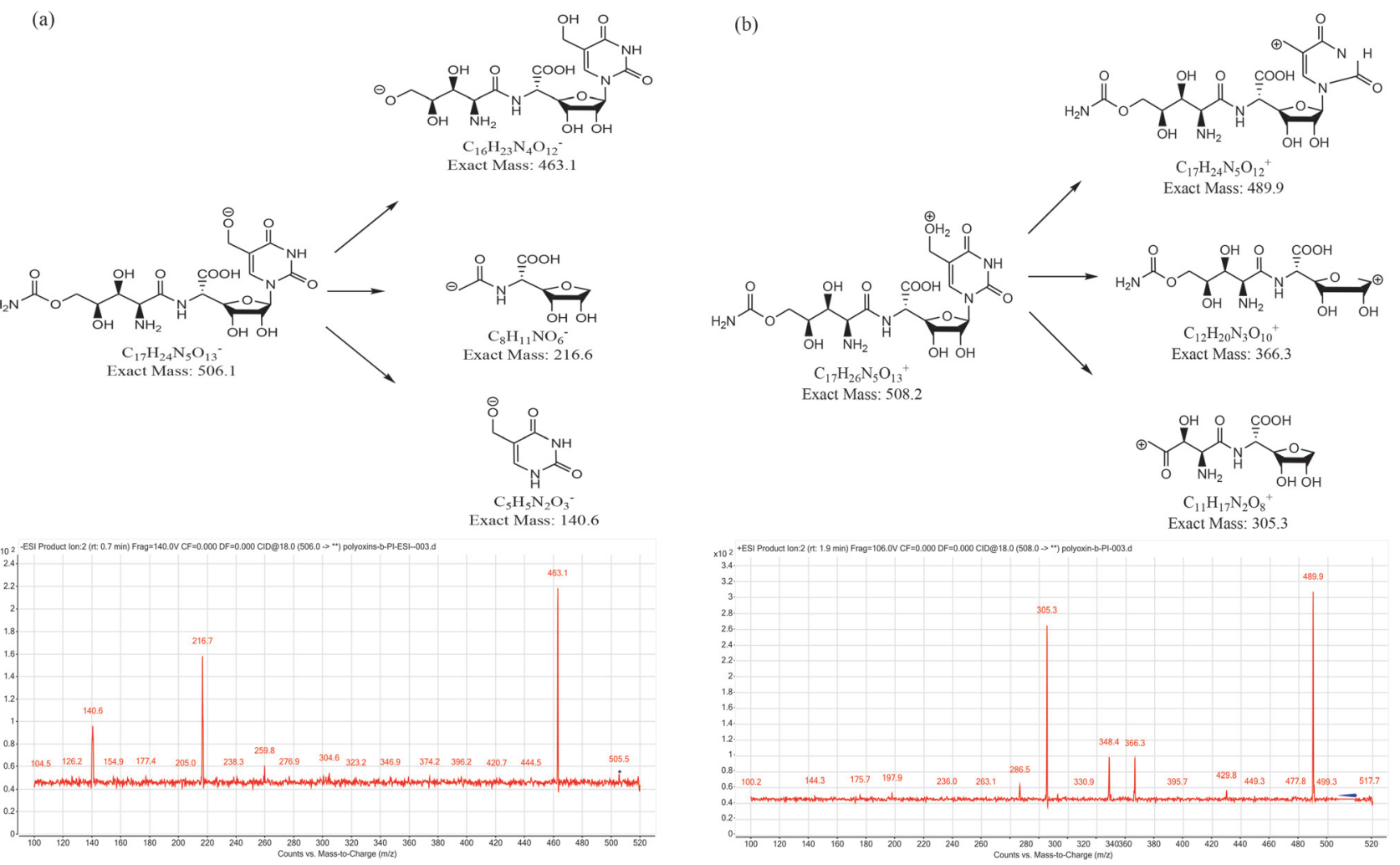

Figure 5. Mass fragmentation pathway and MS/MS spectrum of polyoxin B in negative ion mode (a) and positive ion mode (b) 
Table 3. Regression equation, correlation coefficients $\left(R^{2}\right)$, and half-lives for polyoxin B in soil and cucumber

\begin{tabular}{lcccc}
\hline Matrix & $\begin{array}{c}\text { Locality } \\
\text { (year) }\end{array}$ & Regression equation & $R^{2}$ & $\begin{array}{c}\text { Half-life } \\
\text { (days) }\end{array}$ \\
\cline { 3 - 5 } Cucumber & GX (2012) & $y=0.7437 e^{-0.242 x}$ & 0.9917 & 2.9 \\
& GX (2013) & $y=0.3004 e^{-0.184 x}$ & 0.8864 & 3.8 \\
& HN (2012) & $y=0.5523 e^{-0.196 x}$ & 0.9658 & 3.5 \\
& HN (2013) & $y=0.6565 e^{-0.226 x}$ & 0.9506 & 3.1 \\
& AH (2012) & $y=0.6583 e^{-0.162 x}$ & 0.9760 & 4.3 \\
& AH (2013) & $y=0.8011 e^{-0.267 x}$ & 0.974 & 2.5 \\
& & & & \\
Soil & GX (2012) & $y=0.3083 e^{-0.15 x}$ & 0.7654 & 4.6 \\
& GX (2013) & $y=0.4604 e^{-0.17 x}$ & 0.7849 & 4.1 \\
& HN (2012) & $y=0.6253 e^{-0.144 x}$ & 0.9785 & 5.0 \\
& HN (2013) & $y=0.6875 e^{-0.164 x}$ & 0.9672 & 4.2 \\
& AH (2012) & $y=0.6023 e^{-0.187 x}$ & 0.9378 & 3.7 \\
& AH (2013) & $y=0.4553 e^{-0.169 x}$ & 0.8031 & 4.1 \\
\hline
\end{tabular}

MRLs $(0.05 \mathrm{mg} / \mathrm{kg})$ established by China [22]. Based on these results, we therefore suggest that the PHIs of the last spraying of the cucumber should be 3 days.

The results showed that polyoxin B dissipated faster in cucumber than soil and the mean half-lives were 3.4 and 4.2 days, respectively. Growth dilution effect of cucumber may cause it. It was seen that more than $81.8 \%$ of the initial residues of polyoxin $\mathrm{B}$ had dissipated in soil within 10 days. Also, more than $68.3 \%$ of initial residues of polyoxin B had dissipated in cucumber within 5 days. Moreover, almost $81.1 \%$ of the residues had dissipated in cucumber by the 10th day. Initial deposits of polyoxin B in cucumber and soil differed among the three experimental sites. Dissipation of polyoxin B in soil was faster in Guangxi than Hunan and Anhui provinces, while dissipation of polyoxin B in cucumber was faster in Anhui than Guangxi and Hunan provinces. It might be affected by some physical and chemical factors of polyoxin B, climatic conditions, soil characteristics, or microorganisms.

\section{Conclusions}

A rapid and sensitive method for the analysis of polyoxin B in cucumber and soil has been developed using LC-MS/MS combined with the modified QuEChERS method. High recoveries of over $83.0 \%$ were obtained with RSDs of less than $5.2 \%$. In this study, the validation parameters of the method in terms of analytical linearity, reproducibility, precision, recovery, etc. showed that the proposed method meets the requirements for polyoxin B analysis. The dissipation dynamics showed that polyoxin B dissipated faster in cucumber than soil. The terminal residues of polyoxin B in cucumber PHIs of 3 days and 5 days are less than $0.05 \mathrm{mg} / \mathrm{kg}$. The results confirm the feasibility of the proposed method, which can be easily implemented for routine testing and monitoring of polyoxin B residues in cucumber and soil. Furthermore, these results will contribute to establish the MRLs of polyoxin B for cucumber in China. Therefore, the developed method could be employed for the routine analysis of polyoxin B in other agricultural crops.

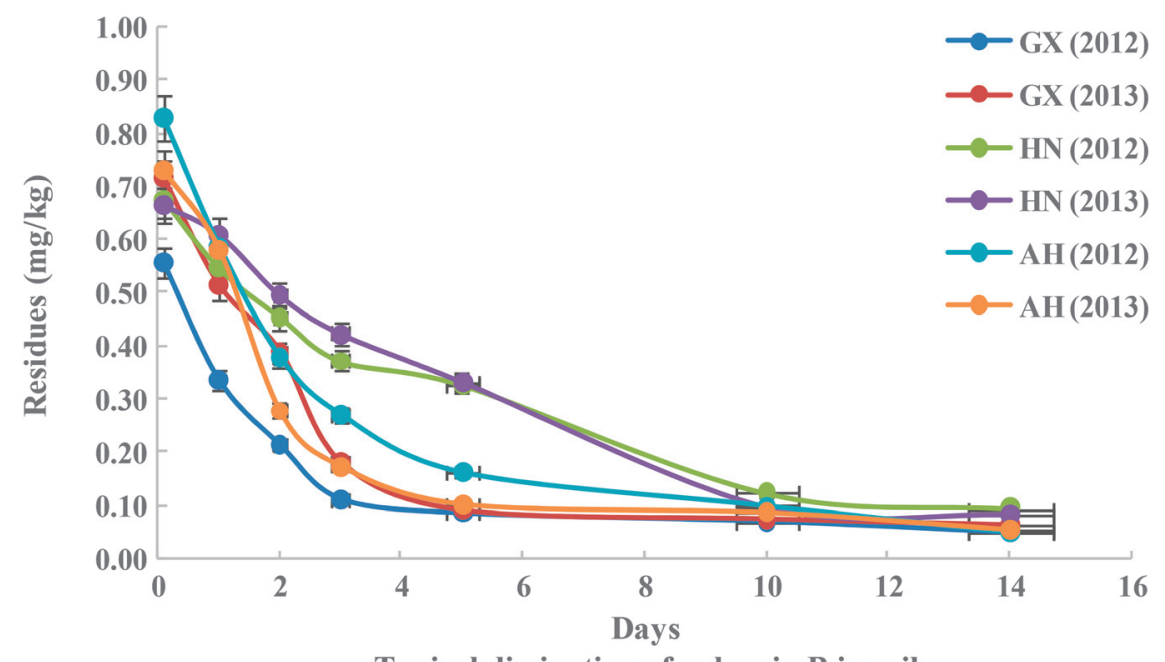

Typical dissipation of polyoxin B in soil

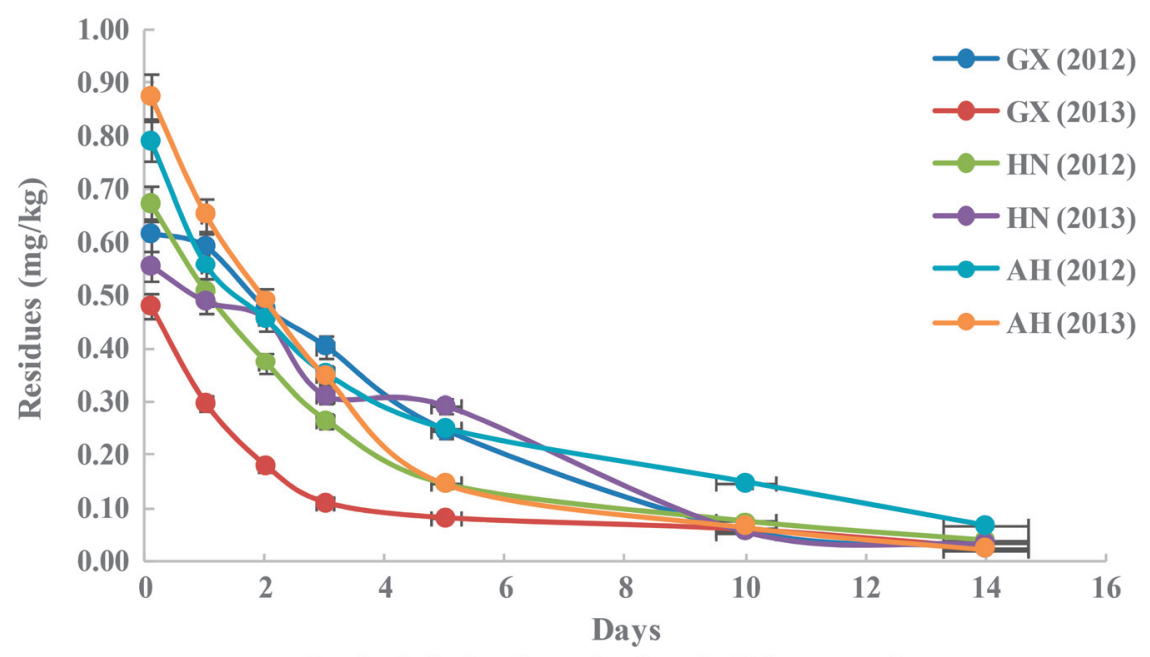

Typical dissipation of polyoxin B in cucumber

Figure 6. Typical dissipation of polyoxin B in soil and cucumber 


\section{Conflict of Interest}

The authors declare no financial or other conflicts of interest.

Acknowledgment. This work was supported by National Key R\&D projects of comprehensive evaluation and optimization of environmental effects of chemical fertilizers and pesticides in tea garden (No. 2016YFD0201208-4), Guangxi Key Laboratory Cultivation Base of Agro-Environment and Agro-Product Safety (2016,133), and Guangxi science and technology major projects (AA17204043).

\section{References}

1. Isono, K.; Nagatsu, J.; Kawashima, Y.; Suzuki, S. Agric. Biol. Chem. $1965,29,848$

2. Li, R.; Xie, Z.; Tian, Y.; Yang, H.; Chen, W.; You, D.; Liu, G.; Deng, Z; Tan, H. Microbiol. 2009, 155, 1819-1831.

3. Reuveni, M.; Cohen, H.; Zahavi, T.; Venezian, A. Crop Prot. 2000, 19, 393-399.

4. Xu, W.; Yang, S.; Bhadury, P.; He, J.; He, M.; Gao, L.; Hu, D.; Song, B. Pest. Biochem. Physiol. 2011, 101, 6-15.

5. Ji, Q.; Yang, D.; Wang, X.; Chen, C.; Deng, Q.; Ge, Z.; Yuan, L.; Yang, X.; Liao, F. Bioorgan. Med. Chem. 2014, 22, 3405-3413.

6. Arakawa, T.; Yukuhiro, F.; Noda, H. Appl. Entomol. Zool. 2008, 43, 173-181.

7. Sun, L.; Chen, W.; Deng, Z.; Zhong, J. Process Biochem. 2009, 44, 361-364.

8. Hwang, B. K.; Yun, J. H. J. Phytopathol. 1986, 115, 305-312.

9. Li, J.; Li, L.; Tian, Y.; Niu, G.; Tan, H. Meta. Eng. 2011, 13, 336-344.

10. Zhai, L.; Lin, S.; Qu, D.; Hong, X.; Bai, L. Meta. Eng. 2012, 14, 388-393.

11. Reuveni, M.; Sheglov, D. Crop Prot. 2002, 21, 951-955.

12. Reuveni, M. Crop Prot. 2001, 20, 663-668.

13. Arakawa, T. Appl. Entomol. Zool. 2008, 43, 167-171.

14. Gow, L.; Selitrenikoff, C. Curr. Microbiol. 1984, 11, 211-216.

15. Yu, F.; Song, X.; Jiang, J.; Liu, W.; Lei, Q. Agriochem. 2008, 47, 188-189.

16. Li, Y.; Zhou, M.; Ma, Y.; Si, C.; Mi, J.; Liu, C.; Chen, H. J. Instrument. Anal. 2011, 30, 537-542, 548 .

17. Zhao, P.; Wang, L.; Luo, J.; Li, J.; Pan, C. J. Sep. Sci. 2012, 35, 153-8.
18. Qin, Y.; Zhang, J.; Zhang, Y.; Li, F.; Han, Y.; Zou, N.; Xu, H.; Qian, M.; Pan, C. J. Chromatog. A 2016, 1462, 19-26.

19. Zhang, F.; Wang, L.; Zhou, L.; Wu, D.; Pan, H.; Pan, C. Ecotoxicol. Environ. Safe. 2012, 78, 116-122.

20. Qin, Y.; Zhao, P.; Fan, S.; Han, Y.; Li, Y.; Zou, N.; Song, S.; Zhang, Y.; Li, F.; Li, X.; Pan, C. J. Chromatog. A 2015, 1385, 1-11.

21. http://202.127.42.84/tbt-sps/mrlsdb/queryMrlsdb.do.

22. Ministry of Agriculture of the People's Republic of China. GB 2763-2016 National food safety standard-Maximum residue limits for pesticides in food. Beijing: Standards Press of China, China, CN, 2016.

23. Rahman, M. M.; Abd El-Aty, A. M.; Kim, S.; Na, T.; Shin, H.; Hong, S.; Shim, J. Food Chem. 2017, 221, 683-688.

24. Lehotay, S. J.; Son, K. A.; Kwon, H.; Koesukwiwat, U.; Fu, W.; Mastovska, K.; Hoh, E.; Leepipatpiboon, N. J. Chromatog. A 2010, 1217, 2548-2560.

25. Chen, G.; Cao, P.; Liu, R. Food Chem. 2011, 125, 1406-1411.

26. Bruzzoniti, M. C.; Checchini, L; De Carlo, R. M; Orlandini, S.; Rivoria, L.; Bubba, M. D. Anal. Bioanal. Chem. 2014, 406, 4089-4116.

27. Yogendrarajah, P.; Poucke, C. V.; Meulenaer, B. D.; Saeger, S. D. J. Chromatog. A 2013, 1297, 1-11.

28. https://www.wunderground.com/history/airport/ZSOF/2012/5/1/MonthlyHistory. $\mathrm{html}$ ?req city $=$ ZSOF\&req state $=34 \&$ req statename $=$ China\&reqdb.zip $=00000 \&$ reqdb. magic $=623 \&$ reqdb. $w$ mo $=58321$.

29. https://www.wunderground.com/history/airport/ZSOF/2013/2/1/MonthlyHistory. $\mathrm{html}$ ?req city $=$ ZSOF\&req state $=34 \&$ req statename $=$ China\&reqdb.zip $=00000 \&$ reqdb. magic $=623 \&$ reqdb. $w m o=58321$.

30. https:/www.wunderground.com/history/airport/ZGNN/2012/5/1/MonthlyHistory. $\mathrm{html}$ ?req_city $=$ Nanning\&req_state $=\&$ req_statename $=$ China\&reqdb.zip $=\&$ reqdb. magic $=\&$ reqdb. $w$ mo $=$.

31. https://www.wunderground.com/history/airport/ZGNN/2013/2/1/MonthlyHistory. html?req city $=$ Nanning\&req state $=\&$ req statename $=$ China\&reqdb.zip $=\&$ reqdb . magic $=\&$ reqdb. $w m o=$

32. https://www.wunderground.com/history/airport/ZGHA/2012/5/1/MonthlyHistory. $\mathrm{html}$ ?req_city $=$ ZGHA\&req_state $=43 \&$ req $\_$statename $=C$ hina\&reqdb.zip $=00000 \&$ reqdb. magic $=103 \&$ reqdb. $w$ mo $=$ WZGHA.

33. https://www.wunderground.com/history/airport/ZGHA/2013/2/1/MonthlyHistory. html? req_city $=$ ZGHA\&req_state $=43 \&$ req_statename $=C$ China\&reqdb.zip $=00000 \&$ reqdb.magic $=103 \&$ reqdb. $w$ mo $=$ WZGHA.

34. Zhou, Z.; Wang, C.; Zheng, M.; Jiang, L.; Lou, Y. Soil. Biol. Biochem. 2017, 115, 433-441.

35. Fan, K.; Cardona, C.; Li, Y.; Shi, Y.; Xiang, X.; Shen, C.; Wang, H.; Gilbert, J. A.; Chu, H. Soil. Biol. Biochem. 2017, 113, 275-284. 